\title{
Degradation kinetics of vitamins in premixes for pig: effects of choline, high concentrations of copper and zinc, and storage time
}

\author{
Pan Yang ${ }^{1}$, Hua Kai Wang ${ }^{1}$, Min Zhu ${ }^{1,2}$, Long Xian $\mathrm{Li}^{1}$, and Yong Xi Ma ${ }^{1,3, *}$
}

\author{
* Corresponding Author: Yong Xi Ma \\ Tel: +86-10-6273-3588, Fax: +86-10-6273-3688, \\ E-mail: mayongxi2005@163.com \\ ${ }^{1}$ State Key Laboratory of Animal Nutrition, \\ College of Animal Science and Technology, \\ China Agricultural University, Beijing 100193, \\ China \\ 2 Feed Research Center, Liyuan Group, \\ Guangxi 541004, China \\ ${ }^{3}$ Ministry of Agriculture and Rural Affairs \\ Feed Industry Centre, Beijing 100193, China \\ ORCID \\ Pan Yang \\ https://orcid.org/0000-0002-2944-8509 \\ Hua Kai Wang \\ https://orcid.org/0000-0002-8180-1453 \\ Min Zhu \\ https://orcid.org/0000-0002-2009-8418 \\ Long Xian Li \\ https://orcid.org/0000-0002-3816-1788 \\ Yong Xi Ma \\ https://orcid.org/0000-0001-7892-5618
}

Submitted Jan 16, 2020; Revised Mar 2, 2020; Accepted May 29, 2020
Objective: The present work was undertaken to evaluate the effects of storage time, choline chloride, and high concentrations of $\mathrm{Cu}$ and $\mathrm{Zn}$ on the kinetic behavior of vitamin degradation during storage in two vitamin premixes and four vitamin-trace mineral (VTM) premixes.

Methods: Two vitamin premixes (with or without $160,000 \mathrm{mg} / \mathrm{kg}$ of choline) were stored at $25^{\circ} \mathrm{C}$ and $60 \%$ humidity. Besides, four VTM premixes were used to evaluate the effects of choline ( 0 vs $40,000 \mathrm{mg} / \mathrm{kg}$ ) and trace minerals (low $\mathrm{CuSO}_{4}+\mathrm{ZnO}$ vs high $\mathrm{CuSO}_{4}+\mathrm{ZnO}$ ) on vitamin stability in VTM premixes stored in room, and the VTM premixes were stored in room temperature at $22^{\circ} \mathrm{C}$. Subsamples from each vitamin and VTM premix were collected at $0,1,2,3,6$, and 12 months. The retention of vitamin $A(V A)$, vitamin $\mathrm{D}_{3}\left(\mathrm{VD}_{3}\right)$, vitamin $\mathrm{E}(\mathrm{VE})$, vitamin $\mathrm{K}_{3}\left(\mathrm{VK}_{3}\right)$, vitamin $\mathrm{B}_{1}\left(\mathrm{VB}_{1}\right)$, vitamin $\mathrm{B}_{2}\left(\mathrm{VB}_{2}\right)$, vitamin $\mathrm{B}_{3}\left(\mathrm{VB}_{3}\right)$, vitamin $\mathrm{B}_{5}\left(\mathrm{VB}_{5}\right)$, and vitamin $\mathrm{B}_{6}\left(\mathrm{VB}_{6}\right)$ in vitamin premixes and VTM premixes during storage was determined. The stability of vitamins in vitamin premixes and VTM premixes was determined and reported as the residual vitamin activity (\% of initial) at each sampling point.

Results: The effect of choline on $\mathrm{VK}_{3}$ retention was significant in vitamin premixes $(\mathrm{p}<0.05)$. The negative effect of storage time was significant for the retentions of $\mathrm{VD}_{3}, \mathrm{VK}_{3}, \mathrm{VB}_{1}, \mathrm{VB}_{2}$, $\mathrm{VB}_{5}$, and $\mathrm{VB}_{6}$ in vitamin premix $(\mathrm{p}<0.05)$. For $\mathrm{VTM}$ premixes, negative effect of storage time was significant $(\mathrm{p}<0.05)$ for the losses of vitamin in VTM premixes. Choline and high concentrations of $\mathrm{Cu}$ and $\mathrm{Zn}$ significantly increased $\mathrm{VA}, \mathrm{VK}_{3}, \mathrm{VB}_{1}$, and $\mathrm{VB}_{2}$ loss during storage $(\mathrm{p}<0.05)$. The supplementation of high concentrations of $\mathrm{Cu}$ and $\mathrm{Zn}$ significantly decreased the concentrations of $\mathrm{VD}_{3}$ and $\mathrm{VB}_{6}(\mathrm{p}<0.05)$ in $\mathrm{VTM}$ premixes at extended storage time.

Conclusion: The maximum vitamin stability was detected in vitamin and VTM premixes containing no choline or excess $\mathrm{Cu}$ and $\mathrm{Zn}$. The results indicated that extended storage time increased degradation of vitamin in vitamin or VTM premixes. These results may provide useful information for vitamin and VTM premixes to improve the knowledge of vitamin in terms of its stability.

Keywords: Choline; Copper; Premix; Vitamin Stability; Storage Time; Zinc

\section{INTRODUCTION}

Vitamin and vitamin-trace mineral (VTM) premixes are designed for supplemental nutritional support to animals who are unable to ingest adequate amounts of natural feedstuffs $[1,2]$. Choline serves some essential biological functions in young animals $[3,4]$, such as improving fat transport and metabolism in the liver, source of methyl donors for methionine regeneration from homocysteine, building and maintaining cell wall structure, and supporting nervous system function. 
In the post-weaning period, the stress of being removed from the sow and mixing into a new environment results in perturbations of gut microbiota and lowered defenses against pathogen entry for piglets, which can lead to increased risk of disease $[5,6]$. Post-weaning diarrhea is one of the most common causes of mortality for weanling pigs, and hence greatly impaired growth performance of pigs $[5,6]$. In practical application, the inclusion of high concentrations of zinc oxide $(\mathrm{ZnO})$ and copper sulfate $\left(\mathrm{CuSO}_{4}\right)$ in weaned pig diets can improve the growth performance and decrease diarrhea incidence [5-7]. All of these treatments may affect the formulation of the ingredients in premixes, leading to bioavailability loss of necessary nutrients. In addition, premixes are often not consumed immediately after manufacturing and can be degraded due to several factors, such as the length of storage and premix compositions. (e.g. choline chloride and high concentrations of metal ions) [3,8-11]. Numerous reports have discussed the stability of vitamins under various conditions such as storage and processing [8-11]. Vitamins may be unstable to heat and light as well as exposure to acid, alkali, air, and moisture. The degradation of vitamin activity in premixes and complete feed during storage may result in hidden depressions in growth, feed efficiency, and disease resistance due to the subclinical vitamin deficiencies $[3,8,11]$. For this reason, the vitamin content should be evaluated after manufacturing and storage in order to ensure the amount provided.

However, studies on the stability of vitamins in vitamin premix and VTM premix are limited. In addition, these factors (choline chloride and high concentrations of $\mathrm{CuSO}_{4}$ and $\mathrm{ZnO}$ ) in premixes have received limited research attention, and it is unclear which vitamins in vitamin or VTM premixes are vulnerable when choline and high concentrations of $\mathrm{Cu}$ and $\mathrm{Zn}$ are present. Therefore, the objectives of this study were to i) determine the rate of vitamin loss in vitamin or VTM premixes and the effects of choline and high concentrations of $\mathrm{Cu}$ and $\mathrm{Zn}$ on the stability of vitamins during storage and ii) to develop vitamin retention prediction models based on storage time.

\section{MATERIALS AND METHODS}

\section{Experimental design}

This study was conducted at the State Key Laboratory of Animal Nutrition at China Agricultural University (Beijing, China) and Ministry of Agriculture and Rural Affairs Feed Efficacy and Safety Evaluation Center (Beijing, China). Approval from the Animal Care and Use Committee was not obtained for this experiment because no animals were used.

\section{Chemical reagents}

Deionized water $(18 \mathrm{M} \Omega \cdot \mathrm{cm}$ ) from a Millipore Milli-Q (Bed- ford, MA, USA) water purification system was used to prepare all aqueous solutions. Standard for retinyl esters, cholecalciferol, $a$-tocopherol acetate, menadione, thiamine, riboflavin, pyridoxine, niacin and pantothenic acid were purchased from Sigma-Aldrich (Fluka, Sigma-Aldrich, Steinheim, Germany). The methanol and acetonitrile of high-performance liquid chromatography (HPLC) grade were used for HPLC analysis and were obtained from Fisher Scientific (Pittsburg, PA, USA). All the other chemicals used were analytical grade and purchased from Sinopharm Chemical Reagent LTD (Beijing, China).

\section{Premix formulation and treatments}

Two vitamin premixes (containing no trace minerals) were formulated by commercial vitamins. The vitamin manufacturer is not disclosed in order to protect proprietary information. The manufacturing dates of all vitamins were obtained from the original suppliers to ensure that the products were within 6 months of manufacture and were not expired. The vitamin premixes were designed to be added at a rate of $2.5 \mathrm{~g} / \mathrm{kg}$ of the diet. The specific vitamin composition and inclusion level were set to mimic common swine industry vitamin premixes. One of vitamin premixes contained choline, another vitamin premix without choline (Table 1). The choline chloride concentration in vitamin premix was measured via chromatography [12].

Four VTM premixes were formulated to contain the same level of vitamins for weanling piglets. The VTM premixes were designed to be added at a rate of $10 \mathrm{~g} / \mathrm{kg}$ of the diet, which is common in practice. Compositions of VTM premixes were shown in Table 1. Vitamin levels met or exceeded the requirement of NRC [13], which were chosen to represent the "typical" industry levels based on informal surveys of vitamin levels in commercially available premixes. The amounts of each vitamin used in each premix are shown in Table 2. Choline was added to VTM premixes 2 and 4 . The choline chloride concentration in VTM premix was determined using chromatography [12]. The VTM premixes 1 to 4 were formulated to meet or exceeded NRC requirements for copper $(\mathrm{Cu})$, iodine $(\mathrm{I})$, iron $(\mathrm{Fe})$, manganese $(\mathrm{Mg})$, selenium (Se), and zinc ( $\mathrm{Zn}$ ) for piglets [13]. The VTM premixes 3 and 4 contained 20,000 mg/kg of $\mathrm{Cu}$ added as $\mathrm{CuSO}_{4}$ and $225,000 \mathrm{mg} / \mathrm{kg}$ per diet of $\mathrm{Zn}$ added as $\mathrm{ZnO}$, which could provide $200 \mathrm{mg} / \mathrm{kg}$ of $\mathrm{Cu}$ and 2,250 mg/kg Zn in diet. The reason for choosing these levels of $\mathrm{Cu}$ and $\mathrm{Zn}$ is that weanling pig premixes commonly have higher concentrations of $\mathrm{Cu}$ and $\mathrm{Zn}$ as an antimicrobial and improve growth performance [5-7].

\section{Premix preparation and storage}

Vitamin and VTM mineral premixes were manufactured at a commercial vitamin premix plant. Each of the two vitamin 
Table 1. Composition of the vitamin and vitamin-trace mineral premixes ${ }^{1)}$

\begin{tabular}{|c|c|c|c|c|c|c|}
\hline Item & Vitamin premix 1 & Vitamin premix 2 & VTM premix 1 & VTM premix 2 & VTM premix 3 & VTM premix 4 \\
\hline \multicolumn{7}{|l|}{ Vitamin ${ }^{2)}$ (unit/kg) } \\
\hline VA (IU) & $5,400,000$ & $5,400,000$ & $1,350,000$ & $1,350,000$ & $1,350,000$ & $1,350,000$ \\
\hline $\mathrm{VD}_{3}(\mathrm{IU})$ & $1,200,000$ & $1,200,000$ & 300,000 & 300,000 & 300,000 & 300,000 \\
\hline VE (IU) & 12,000 & 12,000 & 3,000 & 3,000 & 3,000 & 3,000 \\
\hline $\mathrm{VK}_{3}(\mathrm{mg})$ & 1,200 & 1,200 & 300 & 300 & 300 & 300 \\
\hline $\mathrm{VB}_{1}(\mathrm{mg})$ & 1,200 & 1,200 & 300 & 300 & 300 & 300 \\
\hline $\mathrm{VB}_{2}(\mathrm{mg})$ & 2,400 & 2,400 & 600 & 600 & 600 & 600 \\
\hline $\mathrm{VB}_{3}(\mathrm{mg})$ & 12,000 & 12,000 & 3,000 & 3,000 & 3,000 & 3,000 \\
\hline $\mathrm{VB}_{5}(\mathrm{mg})$ & 7,200 & 7,200 & 1,800 & 1,800 & 1,800 & 1,800 \\
\hline $\mathrm{VB}_{6}(\mathrm{mg})$ & 1,200 & 1,200 & 300 & 300 & 300 & 300 \\
\hline Folic acid (mg) & 48 & 48 & 12 & 12 & 12 & 12 \\
\hline Biotin (mg) & 12 & 12 & 3 & 3 & 3 & 3 \\
\hline Vitamin $\mathrm{B}_{12}(\mathrm{mg})$ & 9.6 & 9.6 & 2.4 & 2.4 & 2.4 & 2.4 \\
\hline Choline (mg) & - & 160,000 & - & 40,000 & - & 40,000 \\
\hline \multicolumn{7}{|c|}{ Trace minera| ${ }^{3)}(\mathrm{mg} / \mathrm{kg})$} \\
\hline $\mathrm{Cu}$ & - & - & 500 & 500 & 20,000 & 20,000 \\
\hline । & - & - & 14 & 14 & 14 & 14 \\
\hline $\mathrm{Fe}$ & - & - & 10,000 & 10,000 & 10,000 & 10,000 \\
\hline $\mathrm{Mg}$ & - & - & 300 & 300 & 300 & 300 \\
\hline $\mathrm{Se}$ & - & - & 25 & 25 & 25 & 25 \\
\hline $\mathrm{Zn}$ & - & - & 8,000 & 8,000 & 225,000 & 225,000 \\
\hline
\end{tabular}

VTM, vitamin-trace mineral; $V A$, vitamin $A ; V_{3}$, vitamin $D_{3} ; V E$, vitamin $E ; V_{3}$, vitamin $K_{3} ; V_{1}$, vitamin $B_{1} ; V_{2}$, vitamin $B_{2} ; V_{3} ;$ vitamin $B_{3} ; V_{5}$, vitamin $B_{5} ;$ $\mathrm{VB}_{6}$, vitamin $\mathrm{B}_{6}$.

1) Vitamin premixes were designed to be added at a rate of $2.5 \mathrm{~g} / \mathrm{kg}$ of the diet. The VTM premixes were designed to be added at a rate of $10 \mathrm{~g} / \mathrm{kg}$ of the diet. Vitamin premix 1 contained no choline chloride, Vitamin premix 2 contained 160,000 mg/kg of choline chloride. VTM premix 1 contained $500 \mathrm{mg} / \mathrm{kg}$ of $\mathrm{CuSO}_{4}$ and $8,000 \mathrm{mg} / \mathrm{kg}$ of ZnO, VTM premix 2 contained $40,000 \mathrm{mg} / \mathrm{kg}$ of choline chloride, $500 \mathrm{mg} / \mathrm{kg}$ of CuSO4 and 8,000 mg/kg of ZnO. VTM premix 3 contained $20,000 \mathrm{mg} / \mathrm{kg}$ of $\mathrm{CuSO}_{4}$ and $225,000 \mathrm{mg} / \mathrm{kg}$ of ZnO. VTM premix 4 contained $40,000 \mathrm{mg} / \mathrm{kg}$ of choline chloride, 20,000 mg/kg of CuSO and $225,000 \mathrm{mg} / \mathrm{kg}$ of ZnO. Limestone and rice by-product as carriers mix purified forms of vitamins and trace minerals to achieve the pre-determined diet inclusion rate.

2) Vitamin sources: $V A$, retinyl acetate; $V D_{3}$, cholecalciferol; $V E, D$, L-a-tocopherol acetate; $V K_{3}$, menadione sodium bisulfite; $V B_{1}$, thiamine mononitrate; $V B_{2}$, riboflavin; $\mathrm{VB}_{3}$, nicotinic acid; $\mathrm{VB}_{5}$, D-calcium pantothenate; $\mathrm{VB}_{6}$, pyridoxine hydrochloride; $\mathrm{VB}_{7}$, biotin; Vitamin $\mathrm{B}_{9}$, folic acid; Vitamin $\mathrm{B}_{12}$, cyanocobalamin; choline, choline chloride.

3) Trace mineral source: $\mathrm{Cu}, \mathrm{CuSO}_{4} ; \mathrm{I}, \mathrm{Ca}\left(\mathrm{IO}_{3}\right)_{2} ; \mathrm{Fe}, \mathrm{FeSO}_{4} ; \mathrm{Mg}, \mathrm{MnO} ; \mathrm{Se}, \mathrm{NaSeO}_{2} ; \mathrm{Zn}, \mathrm{ZnO}$.

Table 2. Analyzed initial values of vitamin in vitamin and vitamin-trace mineral premixes

\begin{tabular}{|c|c|c|c|c|c|c|}
\hline Item & Vitamin premix 1 & Vitamin premix 2 & VTM premix 1 & VTM premix 2 & VTM premix 3 & VTM premix 4 \\
\hline \multicolumn{7}{|c|}{ Vitamin $^{1)}$ (unit/kg) } \\
\hline VA (IU) & $5,317,420$ & $5,350,883$ & $1,367,333$ & $1,393,358$ & $1,358,165$ & $1,382,106$ \\
\hline VE (IU) & 12,044 & 11,996 & 2,942 & 2,942 & 2,963 & 2,979 \\
\hline $\mathrm{VK}_{3}(\mathrm{mg})$ & 1,171 & 1,164 & 297 & 306 & 294 & 293 \\
\hline $\mathrm{VB}_{3}(\mathrm{mg})$ & 12,167 & 12,015 & 3,017 & 3,019 & 2,984 & 3,018 \\
\hline $\mathrm{VB}_{5}(\mathrm{mg})$ & 7,173 & 7,226 & 1,836 & 1,785 & 1,768 & 1,847 \\
\hline $\mathrm{VB}_{6}(\mathrm{mg})$ & 1,202 & 1,191 & 302 & 296 & 298 & 306 \\
\hline Choline (mg) & - & 166,713 & - & 44,333 & - & 43,448 \\
\hline
\end{tabular}

Values represent means of six replicate samples each analyzed in duplicate.

VTM premix, vitamin-trace mineral premix; VA, vitamin $A_{;} V_{3}$, vitamin $D_{3} ; V E$, vitamin $E_{;} V_{K_{3}}$, vitamin $K_{3} ; V_{1}$, vitamin $B_{1} ; V_{2}$, vitamin $B_{2} ; V_{3} ;$ vitamin $B_{3} ; V_{5}$, vitamin $\mathrm{B}_{5} ; \mathrm{VB}_{6}$, vitamin $\mathrm{B}_{6}$.

1) Vitamin premix 1 contained no choline chloride, Vitamin premix 2 contained 160,000 mg/kg of choline chloride. VTM premix 1 contained $500 \mathrm{mg} / \mathrm{kg}$ of $\mathrm{CuSO}_{4}$ and $8,000 \mathrm{mg} / \mathrm{kg}$ of ZnO, VTM premix 2 contained 40,000 mg/kg of choline chloride, $500 \mathrm{mg} / \mathrm{kg}$ of CuSO4 and 8,000 mg/kg of ZnO. VTM premix 3 contained $20,000 \mathrm{mg} / \mathrm{kg}$ of $\mathrm{CuSO}_{4}$ and $225,000 \mathrm{mg} / \mathrm{kg}$ of ZnO. VTM premix 4 contained $40,000 \mathrm{mg} / \mathrm{kg}$ of choline chloride, 20,000 mg/kg of CuSO $\mathrm{and}_{4}$ $225,000 \mathrm{mg} / \mathrm{kg}$ of $\mathrm{ZnO}$. 
premixes was prepared in six separate batches using an identical procedure ( $7.2 \mathrm{~kg}$ per batch). Each batch represented one replicate and was divided into six-1.2 kg, thick polyethylene bags with plastic ties. Each of the four VTM premixes was prepared in six separate and identical procedure $(18 \mathrm{~kg}$ per batch). Each batch represented one replicate and was divided into six-3.0 kg, thick polyethylene bags with plastic ties. Vitamin premixes were stored in a controlled environment chamber setting at $25^{\circ} \mathrm{C}$ and $60 \%$ relative humidity. The VTM premixes were stored in a storage room $\left(22^{\circ} \mathrm{C}\right)$.

\section{Vitamin sampling, extraction and assays}

Subsample of vitamin and VTM premixes were obtained from each of six replicates at $0,1,2,3,6$, and 12 months. Samples were immediately sent to the Ministry of Agriculture and Rural Affairs Feed Efficacy and Safety Evaluation Center (Beijing, China) used for vitamin analysis. The vitamin A (VA) and $\mathrm{E}$ (VE) were determined by the method 2012.10 [14]. In brief, the sample ( $2 \mathrm{~g}$ ) was mixed with papain solution until dispersed, placed in a $37^{\circ} \mathrm{C} \pm 2^{\circ} \mathrm{C}$ water bath, and extracted by methanol. This extract was analyzed by HPLC (Agilent 1200 Series; Agilent Technologies Inc., Santa Clara, CA, USA). For the extraction of vitamin $\mathrm{D}_{3}$ $\left(\mathrm{VD}_{3}\right)$ from samples, the method of 992.26 [14] was used. In brief, $5 \mathrm{~g}$ sample was transferred to a centrifuge tube and anhydrous ethanol, ascorbic acid, and potassium hydroxide were added. Tubes were placed in a $75^{\circ} \mathrm{C}$ water bath. Subsamples were analyzed by HPLC followed by UV detection at $254 \mathrm{~nm}$. For the determination of vitamin $\mathrm{K}_{3}\left(\mathrm{VK}_{3}\right)$, samples were extracted with trichloromethane. Extract filtered and injected into the HPLC system and UV detection was made at wavelength $251 \mathrm{~nm}$ [15]. For the extraction of watersoluble vitamins (vitamin $B_{1}\left[\mathrm{VB}_{1}\right]$, vitamin $\mathrm{B}_{2}\left[\mathrm{VB}_{2}\right]$, vitamin $\mathrm{B}_{3}\left[\mathrm{VB}_{3}\right]$, vitamin $\mathrm{B}_{5}\left[\mathrm{VB}_{5}\right]$, and vitamin $\mathrm{B}_{6}\left[\mathrm{VB}_{6}\right]$ ) from diets, the procedure of Chen et al [16] was used and modified. Five $\mathrm{g}$ of sample was weighed, extracted with phosphate buffer, heated in a water bath, and sonicated. The supernatants of the extracted samples were stored at $-20^{\circ} \mathrm{C}$ until they were tested. These extracted samples were analyzed using a $250 \times$ $4.5 \mathrm{~mm}, 5 \mu \mathrm{m}$, Eclipse Plus C18 column (Agilent Technologies Inc., USA) on an Agilent liquid chromatograph. The stability of vitamins in vitamin premixes and VTM premixes during storage was determined and reported as the residual vitamin activity (\% of initial) at each sampling point. This time was also convenient for us to compare with previous studies and for developing predicted equations to estimate the vitamin loss. The specific vitamin selected were based on the capacity to complete our respective lab analysis.

\section{Data treatment and statistical analysis}

Normality of the data was verified using the UNIVARIATE procedure of SAS (SAS Inst. Inc., Cary, NC, USA). The BOX-
PLOT procedure of SAS was used to check for outliers. Data were analyzed using the MIXED procedure of SAS (SAS Inst. Inc., USA) to determine the interactive and main effects of choline chloride, high concentrations of $\mathrm{Zn}$ and $\mathrm{Cn}$, and storage time on the activity of vitamins in vitamin and VTM premixes. Results were considered significant at $\mathrm{p} \leq 0.05$ and a tendency at $\mathrm{p} \leq 0.10$. Diagrams were generated using the Excel 2016 (Microsoft Corporation, Redmond, WA, USA). Vitamin retention was modelled using linear regression and non-linear regression. Linear regression to determine vitamin retentions was completed using the PROC REG procedure of SAS. Non-linear regression was performed using PROC NLIN procedures of SAS with exponential model (Eq. (1)). The exponential model is flexible owing to the inclusion of a shape constant in addition to the rate constant and has been employed to describe vitamin degradation kinetics [17].

$$
C_{t}=C_{0} \times e^{-K_{a a} t}
$$

Where $C_{t}$ is the vitamin concentration at a time $t, C_{0}$ is the initial vitamin concentration, $K_{a a}$ is the rate constant. Modelling and analysis of variance were performed using SAS 9.4 (SAS Inst. Inc., USA). The $\mathrm{R}^{2}$ and the root mean square error of prediction (RMSEP) were used to define the best-fit equations.

\section{RESULTS}

\section{Vitamin recovery method validation}

Methods for vitamin analysis in samples were validated with repeatability between-day precision, long-term precision, limits of quantitation, and linearity (data not shown) by the staff of the Ministry of Agriculture and Rural Affairs Feed Efficacy and Safety Evaluation Center (Beijing, China). Calculated values (Table 1) were determined from the minimum declared vitamin concentrations as provided by each product's manufacturer. The initial ( $\mathrm{d} 0$ ) analyzed vitamin concentrations of the vitamin premix, or VTM premixes are reported in Table 2. The analyzed vitamin values in vitamin premix or VTM premixes were similar to calculated vitamin values in vitamin premix or VTM premixes.

\section{Effects of storage time and choline on stability of vitamins in vitamin premixes}

There was no significant interactive effect of storage time and choline on $\mathrm{VA}, \mathrm{VD}_{3}, \mathrm{VE}, \mathrm{VB}_{1}, \mathrm{VB}_{2}, \mathrm{VB}_{3}, \mathrm{VB}_{5}$, and $\mathrm{VB}_{6}$ retention (Table 3 ). The main effect of storage time was significant $(\mathrm{p}<0.01)$ for the retentions of $\mathrm{VD}_{3}, \mathrm{VB}_{1}, \mathrm{VB}_{2}, \mathrm{VB}_{5}$, and $\mathrm{VB}_{6}$ in vitamin premix (Figures 1 to 5 ). The retention of $\mathrm{VK}_{3}$ was significantly influenced by storage time $(\mathrm{p}<0.01)$, choline $(\mathrm{p}<0.01)$ and the interaction between storage time and choline $(\mathrm{p}<0.01$; Table 3; Figure 6$)$. 
Table 3. Probabilities of interactive and main effects of storage time and choline on stability (as defined by percentage of initial vitamin activity) of vitamins in vitamin premixes

\begin{tabular}{|c|c|c|c|}
\hline \multirow{2}{*}{ Item } & \multirow{2}{*}{$\begin{array}{c}\text { Interactive effects } \\
\text { Timexcholine }\end{array}$} & \multicolumn{2}{|c|}{ Main effects } \\
\hline & & Time & Choline \\
\hline VA & 0.628 & 0.096 & 0.076 \\
\hline $\mathrm{VD}_{3}$ & 0.644 & $<0.001$ & 0.958 \\
\hline VE & 0.987 & 0.957 & 0.433 \\
\hline $\mathrm{VK}_{3}$ & $<0.001$ & $<0.001$ & $<0.001$ \\
\hline $\mathrm{VB}_{1}$ & 0.962 & $<0.001$ & 0.273 \\
\hline $\mathrm{VB}_{2}$ & 0.949 & $<0.001$ & 0.742 \\
\hline $\mathrm{VB}_{3}$ & 0.934 & 0.493 & 0.111 \\
\hline $\mathrm{VB}_{5}$ & 0.999 & $<0.001$ & 0.053 \\
\hline $\mathrm{VB}_{6}$ & 0.557 & $<0.001$ & 0.898 \\
\hline
\end{tabular}

$V A$, vitamin $A_{;} V D_{3}$, vitamin $D_{3} ; V E$, vitamin $E_{;} ; K_{3}$, vitamin $K_{3} ; V B_{1}$, vitamin $\mathrm{B}_{1} ; \mathrm{VB}_{2}$, vitamin $\mathrm{B}_{2} ; \mathrm{VB}_{3} ;$ vitamin $\mathrm{B}_{3} ; \mathrm{VB}_{5}$, vitamin $\mathrm{B}_{5} ; \mathrm{VB}_{6}$, vitamin $\mathrm{B}_{6}$.

At 3 months, $\mathrm{VA}, \mathrm{VD}_{3}, \mathrm{VE}, \mathrm{VK}_{3}, \mathrm{VB}_{1}, \mathrm{VB}_{2}, \mathrm{VB}_{3}, \mathrm{VB}_{5}$, and $\mathrm{VB}_{6}$ retained at least $96 \%, 92 \%, 97 \%, 78 \%, 95 \%, 94 \%, 98 \%$, $94 \%$, and $90 \%$ of their initial activity in vitamin premix without choline, respectively. At 12 months, most vitamins retained $76 \%$ to $98 \%$ of the initial vitamin activity, but $\mathrm{VK}_{3}$ was retained $47.64 \%$ of its initial activity in vitamin premix without choline. With increased storage time, VA exhibited a tendency $(\mathrm{p}=0.096)$ for decreased retention in vitamin premixes, but VA exhibited a tendency $(\mathrm{p}=0.076)$ and $\mathrm{VB}_{5}$ was marginally significant $(\mathrm{p}=0.053)$ for decreased retention during extended storage time in vitamin premixes containing choline chloride.

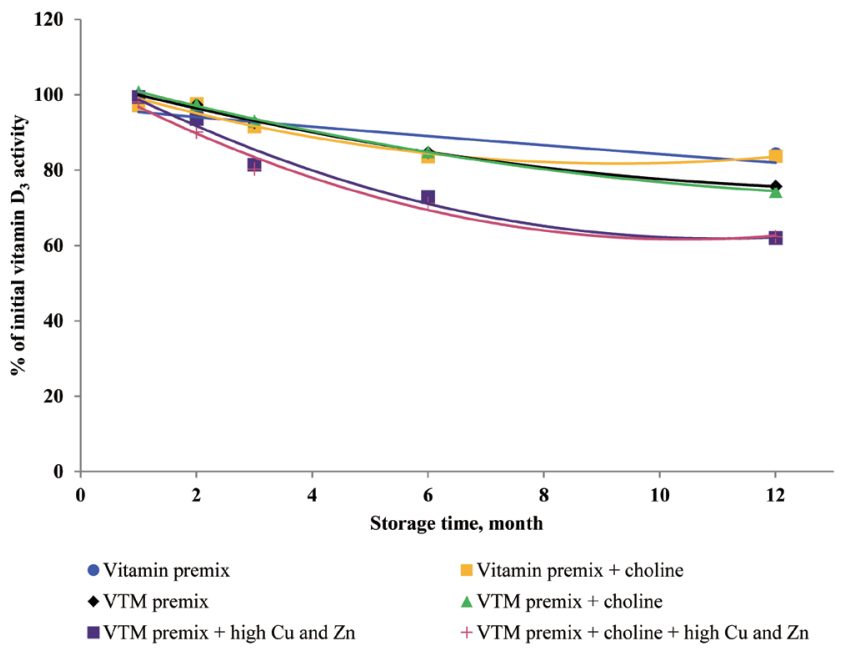

Figure 1. Residual vitamin $D_{3}$ activity (\% of initial) for vitamin premixes and vitamin-trace mineral (VTM) premixes as affected by choline chloride, high concentrations of copper (Cu) and zinc ( $\mathrm{Zn}$ ) and time (1 to 12 months). Each data point is the mean of 6 observations. The $p$-values in vitamin premix (timexcholine, NS; time, $p<0.001$; choline, NS). The $p$-values in VTM premix (timexcholinexCu/Zn, NS; timex choline, NS; timexCu/Zn, $p<0.001$; cholinexCu/Zn, NS; time, $p<0.001$; choline, NS; Cu/Zn, p<0.001)

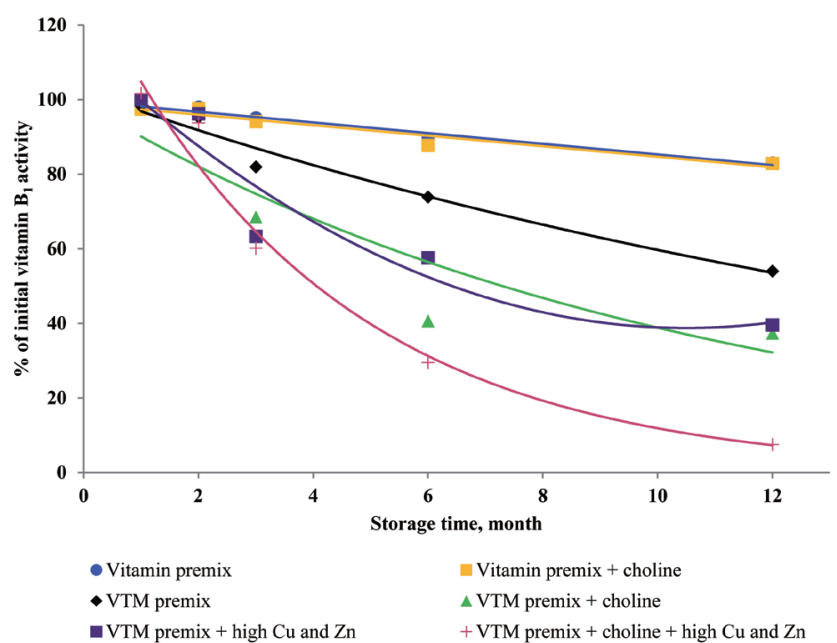

Figure 2. Residual vitamin $B_{1}$ activity (\% of initial) for vitamin premixes and vitamin-trace mineral (VTM) premixes as affected by choline chloride, high concentrations of copper (Cu) and zinc ( $\mathrm{Zn})$ and time (1 to 12 months). Each data point is the mean of 6 observations. The $p$-values in vitamin premix (timexcholine: NS; time, $p<0.001$; choline $\mathrm{NS}$ ). The $p$-values in VTM premix (timexcholinexCu/Zn, $p=0.013$; timexcholine, $p<0.001$; timexCu/Zn, $p<0.001$; cholinexCu/Zn, NS time, $p<0.001$; choline, $p<0.001$; $\mathrm{Cu} / \mathrm{Zn}, \mathrm{p}<0.001$ ).

\section{Effects of storage time, choline, and $\mathrm{Cu}$ and $\mathrm{Zn}$} elements on stability of vitamins in VTM premixes There were interactive effects among storage time, choline chloride and high concentrations of $\mathrm{Cu}$ and $\mathrm{Zn}$ on $\mathrm{VK}_{3}, \mathrm{VB}_{1}$, and $\mathrm{VB}_{2}$ retentions $(\mathrm{p}<0.05)$ (Table 4). Moreover, there were interactive effects between storage time and choline chloride on $\mathrm{VA}, \mathrm{VK}_{3}, \mathrm{VB}_{1}$, and $\mathrm{VB}_{2}$ retentions $(\mathrm{p}<0.05)$. There were

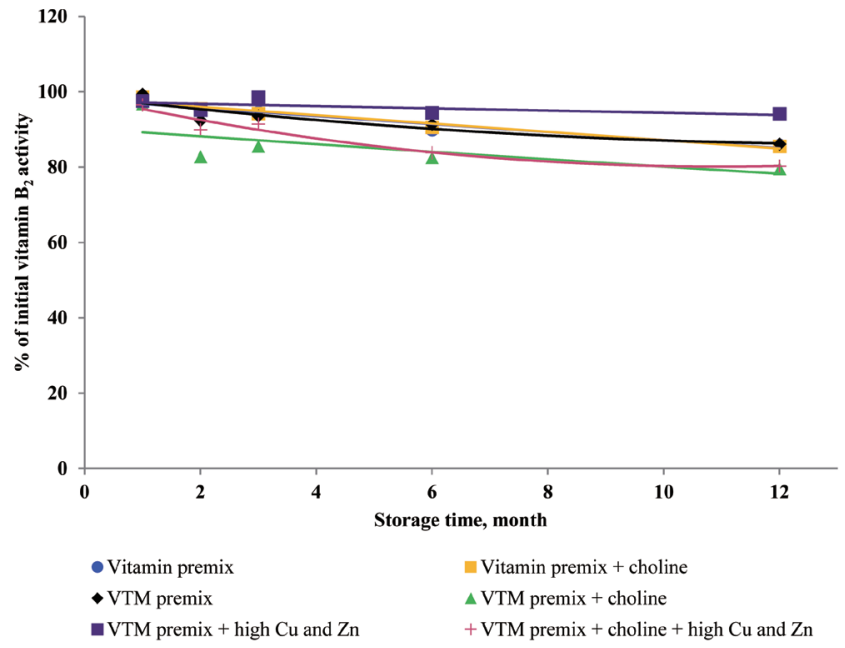

Figure 3. Residual vitamin $B_{2}$ activity (\% of initial) for vitamin premixes and vitamin-trace mineral (VTM) premixes as affected by choline chloride, high concentrations of copper ( $\mathrm{Cu}$ ) and zinc ( $\mathrm{Zn}$ ) and time (1 to 12 months). Each data point is the mean of 6 observations. The $p$-values in vitamin premix (timexcholine, NS; time, $p<0.001$; choline, $N S$ ). The $p$-values in VTM premix (timexcholinexCu/Zn, $p=0.009$; timexcholine, $p<0.001$; timexCu/Zn, $p=0.001$; cholinexCu/Zn, NS; time, $p<0.001$; choline, $p<0.001 ; \mathrm{Cu} / \mathrm{Zn}, \mathrm{p}<0.001$ ). 


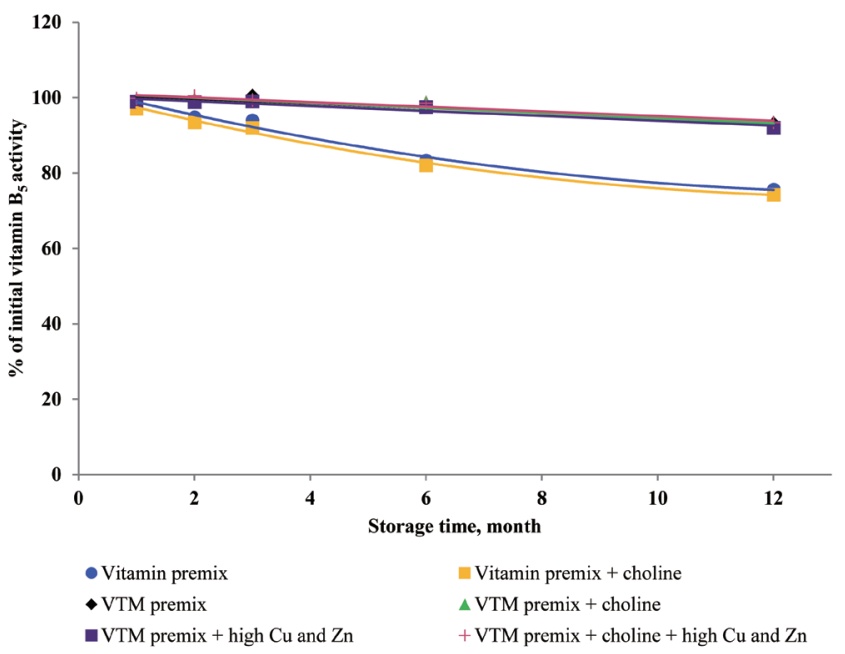

Figure 4. Residual vitamin $B_{5}$ activity (\% of initial) for vitamin premixes and vitamin-trace mineral (VTM) premixes as affected by choline chloride, high concentrations of copper (Cu) and zinc (Zn) and time (1 to 12 months). Each data point is the mean of 6 observations. The $p$-values in vitamin premix (timexcholine, NS; time, $p<0.001$; choline, $p=0.053$ ). The $p$-values in VTM premix (timexcholinexCu/Zn, NS; timexcholine, NS; timexCu/Zn, NS; cholinexCu/Zn, NS; time, p<0.001; choline, NS; Cu/Zn, NS)

interactive effects between storage time and high concentrations of $\mathrm{Cu}$ and $\mathrm{Zn}$ on $\mathrm{VA}, \mathrm{VD}_{3}, \mathrm{VK}_{3}, \mathrm{VB}_{1}, \mathrm{VB}_{2}$, and $\mathrm{VB}_{6}$ retentions $(\mathrm{p}<0.01)$. As well, there were interactive effects between choline chloride and high concentrations of $\mathrm{Cu}$ and $\mathrm{Zn}$ on $\mathrm{VK}_{3}$ retention $(\mathrm{p}<0.01)$. The main effect of storage time on all tested vitamins was significant $(\mathrm{p}<0.01)$, the main effect of choline was significant for $\mathrm{VA}, \mathrm{VK}_{3}, \mathrm{VB}_{1}$, and $\mathrm{VB}_{2}$ retentions $(\mathrm{p}<0.01)$ (Figures 2, 3, 6, and 7), and the main effect of high concentrations of $\mathrm{Cu}$ and $\mathrm{Zn}$ on $\mathrm{VA}, \mathrm{VD}_{3}, \mathrm{VK}_{3}, \mathrm{VB}_{1}$, $\mathrm{VB}_{2}, \mathrm{VB}_{6}$ retentions was significant $(\mathrm{p}<0.01)$ (Figures $1,2,3$, 5,6 , and 7 ).

Extended storage time had negative $(\mathrm{p}<0.01)$ effects on vitamin stability in VTM premix. When VTM premixes were stored, $\mathrm{VE}, \mathrm{VB}_{3}$, and $\mathrm{VB}_{5}$ activities decreased $(\mathrm{p}<0.05)$ (Figures 4,8 , and 9 ) as the duration of storage increased regardless of the choline chloride or high concentrations of

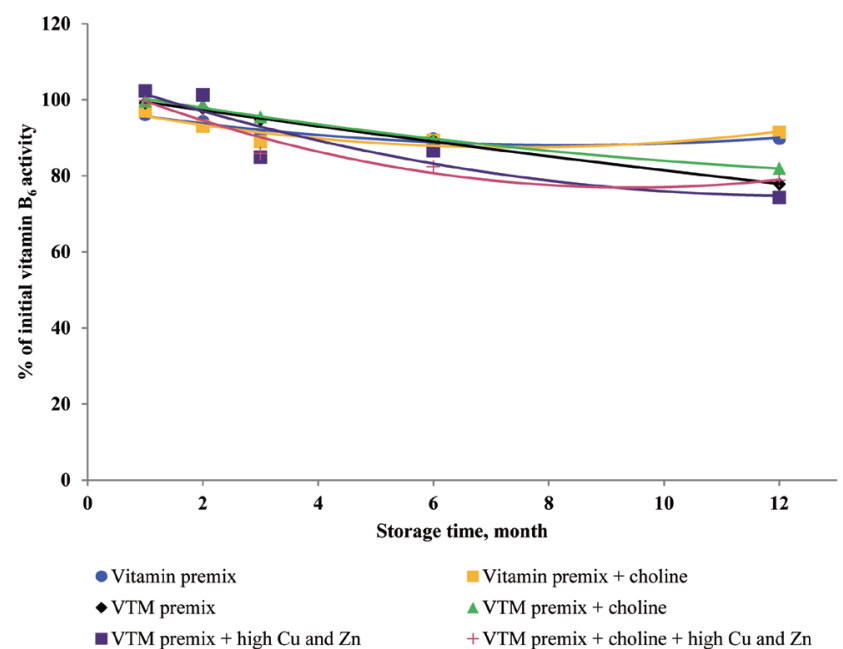

Figure 5. Residual vitamin $B_{6}$ activity (\% of initial) for vitamin premixes and vitamin-trace mineral (VTM) premixes as affected by choline chloride, high concentrations of copper (Cu) and zinc ( $\mathrm{Zn}$ ) and time (1 to 12 months). Each data point is the mean of 6 observations. The $p$-values in vitamin premix (timexcholine, NS; time, $p<0.001$; choline, $\mathrm{NS}$ ). The $p$-values in VTM premix (timexcholinexCu/Zn, NS; timex choline, $p=0.052$; timexCu/Zn, $p<0.001$; cholinexCu/Zn, NS; time, $p<0.001$; choline, NS; Cu/Zn, $p<0.001$ ).

$\mathrm{Cu}$ and $\mathrm{Zn}$. Also, stability of $\mathrm{VA}, \mathrm{VK}_{3}, \mathrm{VB}_{1}$, and $\mathrm{VB}_{2}$ was decreased in VTM premix containing choline and high concentrations of $\mathrm{Cu}$ and $\mathrm{Zn}$. However, the activity of $\mathrm{VB}_{6}$ was rapidly decreased in VTM premix containing high concentrations of $\mathrm{Cu}$ and $\mathrm{Zn}$ (Figure 5).

\section{Kinetic properties of vitamin retention}

The $\mathrm{R}^{2}$, RMSEP, and the prediction equations are presented (Table 5). Analysis of kinetic data suggested that the degradation follows a first-order model. Degradation of $\mathrm{VA}, \mathrm{VD}_{3}$, $\mathrm{VK}_{3}, \mathrm{VB}_{1}$, and $\mathrm{VB}_{6}$ in VTM premix 1 could be suitably modeled based on high $\mathrm{R}^{2}$ value (i.e. $\mathrm{R}^{2}>0.90$ ) of prediction equations. For premix containing chloride choline, equations for predicting retention of $\mathrm{VA}, \mathrm{VD}_{3}, \mathrm{VE}, \mathrm{VK}_{3}, \mathrm{VB}_{3}$, and $\mathrm{VB}_{6}$ in VTM premix 2 were suitably modeled based on high $\mathrm{R}^{2}$ value (i.e. $\mathrm{R}^{2}>0.90$ ), and those had high $\mathrm{R}^{2}$ values compared

Table 4. Probabilities of interactive and main effects of storage time, choline, and Cu and Zn elements on stability (as defined by percentage of initial vitamin activity) of vitamins in vitamin-trace mineral premixes

\begin{tabular}{|c|c|c|c|c|c|c|c|c|c|}
\hline Item & VA & $\mathrm{VD}_{3}$ & VE & $\mathrm{VK}_{3}$ & $\mathrm{VB}_{1}$ & $\mathrm{VB}_{2}$ & $\mathrm{VB}_{3}$ & $\mathrm{VB}_{5}$ & $\mathrm{VB}_{6}$ \\
\hline \multicolumn{10}{|l|}{ Interactive effects } \\
\hline Time $\times$ choline $\times \mathrm{Cu} / \mathrm{Zn}$ & 0.310 & 0.868 & 0.680 & 0.002 & 0.013 & 0.009 & 0.984 & 0.993 & 0.654 \\
\hline Timexcholine & 0.011 & 0.969 & 0.899 & $<0.001$ & $<0.001$ & $<0.001$ & 0.568 & 0.973 & 0.052 \\
\hline TimexCu/Zn & $<0.001$ & $<0.001$ & 0.320 & $<0.001$ & $<0.001$ & 0.001 & 0.729 & 0.993 & $<0.001$ \\
\hline Choline $\times \mathrm{Cu} / \mathrm{Zn}$ & 0.075 & 0.316 & 0.925 & $<0.001$ & 0.603 & 0.653 & 0.846 & 0.500 & 0.104 \\
\hline \multicolumn{10}{|l|}{ Main effects } \\
\hline Time & $<0.001$ & $<0.001$ & $<0.001$ & $<0.001$ & $<0.001$ & $<0.001$ & $<0.001$ & $<0.001$ & $<0.001$ \\
\hline Choline & $<0.001$ & 0.404 & 0.812 & $<0.001$ & $<0.001$ & $<0.001$ & 0.886 & 0.483 & 0.848 \\
\hline $\mathrm{Cu} / \mathrm{Zn}$ & $<0.001$ & $<0.001$ & 0.970 & $<0.001$ & $<0.001$ & $<0.001$ & 0.937 & 0.740 & $<0.001$ \\
\hline
\end{tabular}

$V A$, vitamin $A_{;} V_{D_{3}}$, vitamin $D_{3} ; V E$, vitamin $E_{;} V_{K_{3}}$, vitamin $K_{3} ; V_{1}$, vitamin $B_{1} ; V_{2}$, vitamin $B_{2} ; V_{3} ;$ vitamin $B_{3} ; V_{5}$, vitamin $B_{5} ; V_{6}$, vitamin $B_{6}$. 


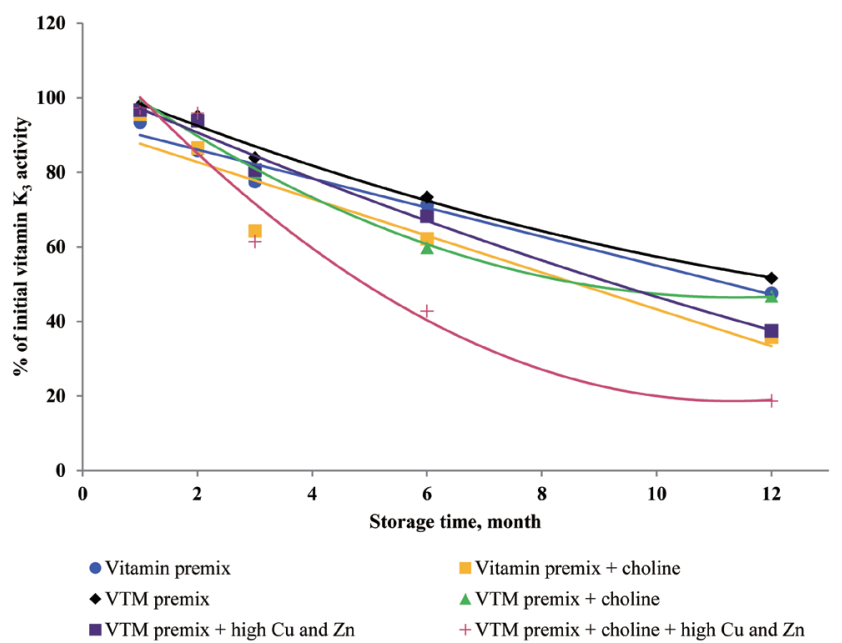

Figure 6. Residual vitamin $\mathrm{K}_{3}$ activity (\% of initial) for vitamin premixes and vitamin-trace mineral (VTM) premixes as affected by choline chloride, high concentrations of copper (Cu) and zinc (Zn) and time (1 to 12 months). Each data point is the mean of 6 observations. The $p$-values in vitamin premix (timexcholine, $p<0.001$; time, $p<0.001$; choline, $p<0.001$ ). The $p$-values in VTM premix (timexcholinexCu/Zn, $p=0.002$; timexcholine, $p<0.001$; timexCu/Zn, $p<0.001$; choline $\times C u / Z n$, $p<0.001$; time, $p<0.001$; choline, $p<0.001 ; \mathrm{Cu} / \mathrm{Zn}, \mathrm{p}<0.001)$.

to equations predicting $\mathrm{VB}_{1}, \mathrm{VB}_{2}$, and $\mathrm{VB}_{5}$. While the ability to predict degradation of $\mathrm{VB}_{2}$ with storage was low $\left(\mathrm{R}^{2}=\right.$ 0.492). In VTM premix 3, equations for predicting retention of $\mathrm{VA}, \mathrm{VD}_{3}, \mathrm{VK}_{3}$, and $\mathrm{VB}_{5}$ had high $\mathrm{R}^{2}$ values (i.e. $\mathrm{R}^{2}>0.90$ ) and thus good fit to predict change in retention with storage time. However, similar ability to predict $\mathrm{VB}_{2}$ degradation

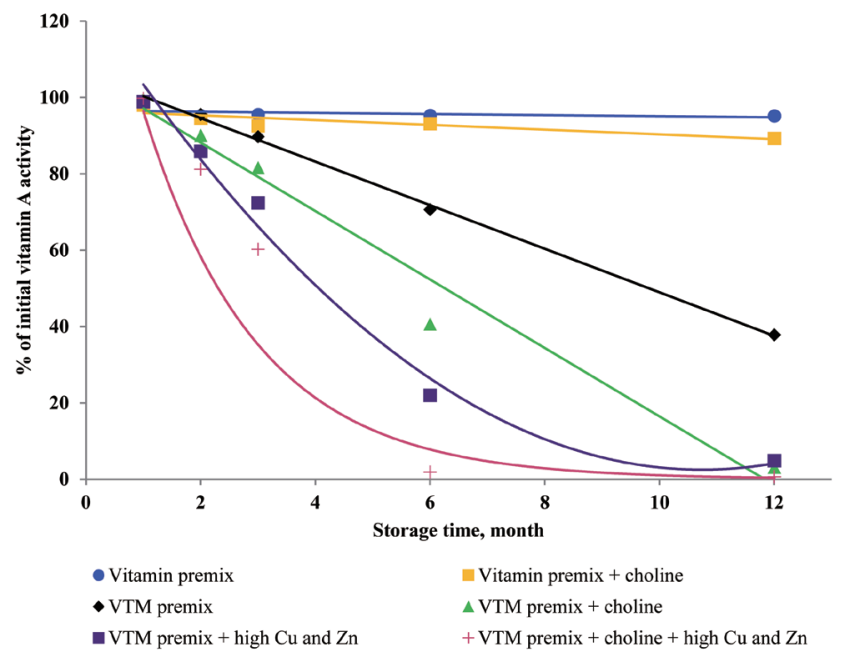

Figure 7. Residual vitamin A activity (\% of initial) for vitamin premixes and vitamin-trace mineral (VTM) premixes as affected by choline chloride, high concentrations of copper (Cu) and zinc ( $\mathrm{Zn}$ ) and time (1 to 12 months). Each data point is the mean of 6 observations. The p-values in vitamin premix (timexcholine, NS; time, NS; choline, NS). The $p$-values in VTM premix (timexcholinexCu/Zn, NS; timexcholine, $p=0.011$; timexCu/Zn, $p<0.001$; cholinexCu/Zn, NS; time, $p<0.001$; choline, $p<0.001 ; \mathrm{Cu} / \mathrm{Zn}, \mathrm{p}<0.001$ ).

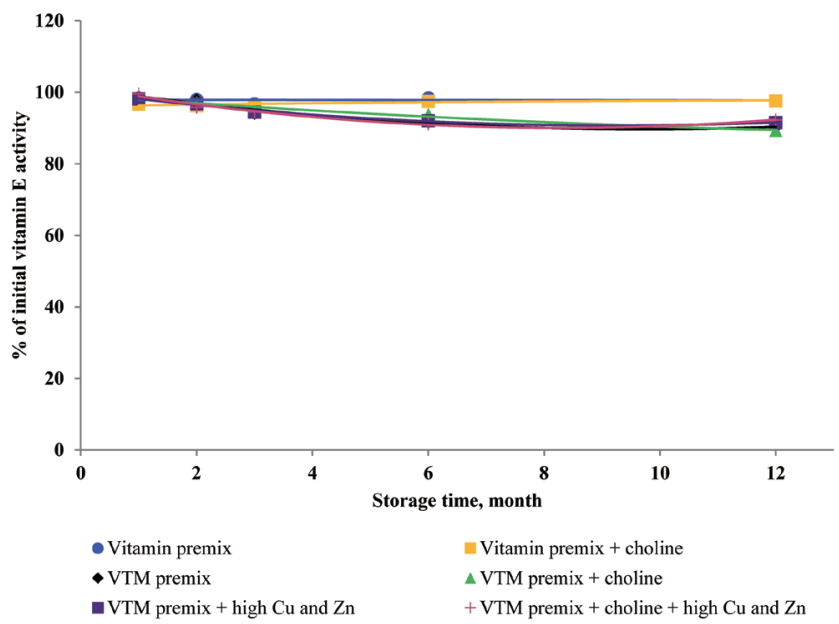

Figure 8. Residual vitamin E activity (\% of initial) for vitamin premixes and vitamin-trace mineral (VTM) premixes as affected by choline chloride, high concentrations of copper (Cu) and zinc ( $\mathrm{Zn}$ ) and time (1 to 12 months). Each data point is the mean of 6 observations. The p-values in vitamin premix (timexcholine, NS; time, NS; choline, NS). The p-values in VTM premix (timexcholinexCu/Zn, NS; timexcholine, NS; timexCu/Zn, NS; cholinexCu/Zn, NS; time, p<0.001; choline, NS; $\mathrm{Cu} / \mathrm{Zn}, \mathrm{NS})$.

with storage time was low $\left(\mathrm{R}^{2}=0.477\right)$. In VTM premix 4 , the equations had high $R^{2}$ (i.e. $\left.R^{2}>0.90\right)$ for predicting retention of $\mathrm{VD}_{3}, \mathrm{VK}_{3}, \mathrm{VB}_{1}$, and $\mathrm{VB}_{5}$ compared to predicting other vitamins.

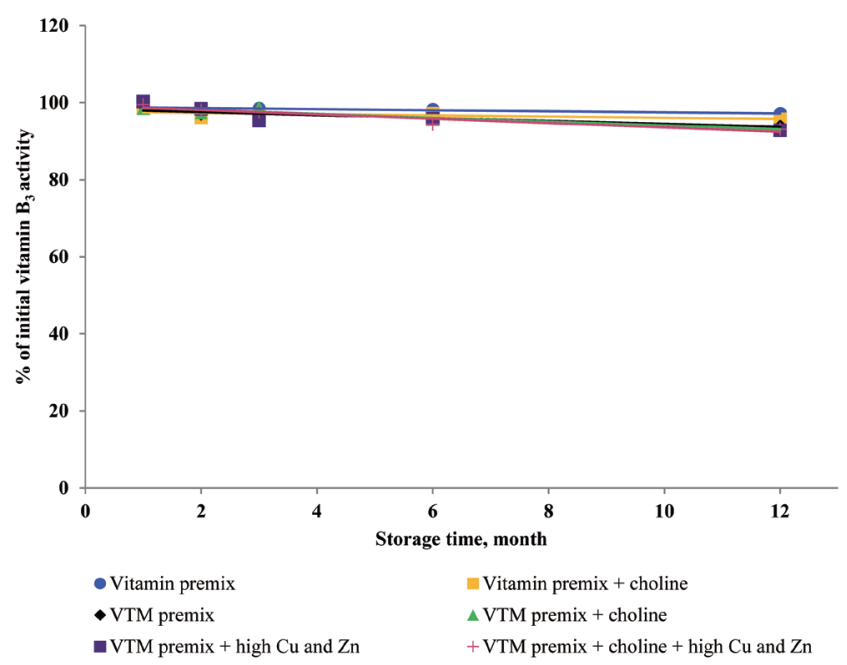

Figure 9. Residual vitamin $B_{3}$ activity (\% of initial) for vitamin premixes and vitamin-trace mineral (VTM) premixes as affected by choline chloride, high concentrations of copper (Cu) and zinc ( $\mathrm{Zn}$ ) and time (1 to 12 months). Each data point is the mean of 6 observations. The p-values in vitamin premix (timexcholine, NS; time, NS; choline, NS). The p-values in VTM premix (timexcholinexCu/Zn, NS; timexcholine, $\mathrm{NS}$; timexCu/Zn, NS; cholinexCu/Zn, NS; time, $p<0.001$; choline, NS $\mathrm{Cu} / \mathrm{Zn}, \mathrm{NS})$. 
Table 5. Prediction equations for vitamin retention (\%) in different vitamin-trace mineral premixes during storage

\begin{tabular}{|c|c|c|c|c|c|c|}
\hline No. & Item & Types ${ }^{1)}$ & Predicted equations $^{2)}$ & $\mathbf{R}^{2}$ & RMSEP & p-value \\
\hline 1 & VA & VTM premix 1 & $y=-5.706 x+106.014$ & 0.998 & 1.158 & $<0.001$ \\
\hline 2 & VA & VTM premix 2 & $y=-8.967 x+106.085$ & 0.974 & 7.573 & 0.002 \\
\hline 3 & VA & VTM premix 3 & $y=144.432 e^{-0.286 x}$ & 0.989 & 0.151 & $<0.001$ \\
\hline 4 & VA & VTM premix 4 & $y=159.533 e^{-0.503 x}$ & 0.882 & 0.944 & 0.018 \\
\hline 5 & $\mathrm{VD}_{3}$ & VTM premix 1 & $y=100.97 e^{-0.025 x}$ & 0.977 & 0.020 & 0.002 \\
\hline 6 & $\mathrm{VD}_{3}$ & VTM premix 2 & $y=102.152 e^{-0.027 x}$ & 0.985 & 0.017 & 0.001 \\
\hline 7 & $\mathrm{VD}_{3}$ & VTM premix 3 & $y=98.338 e^{-0.041 x}$ & 0.919 & 0.063 & 0.010 \\
\hline 8 & $\mathrm{VD}_{3}$ & VTM premix 4 & $y=95.57 e^{-0.039 x}$ & 0.900 & 0.066 & 0.014 \\
\hline 9 & VE & VTM premix 1 & $y=98.111 e^{-0.008 x}$ & 0.797 & 0.020 & 0.042 \\
\hline 10 & VE & VTM premix 2 & $y=98.505 e^{-0.008 x}$ & 0.944 & 0.010 & 0.006 \\
\hline 11 & VE & VTM premix 3 & $y=97.331 e^{-0.006 x}$ & 0.756 & 0.017 & 0.055 \\
\hline 12 & VE & VTM premix 4 & $y=97.288 e^{-0.006 x}$ & 0.554 & 0.026 & 0.146 \\
\hline 13 & $\mathrm{VK}_{3}$ & VTM premix 1 & $y=103.721 e^{-0.058 x}$ & 0.992 & 0.028 & $<0.001$ \\
\hline 14 & $\mathrm{VK}_{3}$ & VTM premix 2 & $y=101.025 e^{-0.068 x}$ & 0.945 & 0.085 & 0.006 \\
\hline 15 & $\mathrm{VK}_{3}$ & VTM premix 3 & $y=108.391 e^{-0.087 x}$ & 0.989 & 0.047 & 0.001 \\
\hline 16 & $\mathrm{VK}_{3}$ & VTM premix 4 & $y=112.062 e^{-0.152 x}$ & 0.975 & 0.125 & 0.002 \\
\hline 17 & $\mathrm{VB}_{1}$ & VTM premix 1 & $y=102.21 e^{-0.054 x}$ & 0.970 & 0.042 & 0.001 \\
\hline 18 & $\mathrm{VB}_{1}$ & VTM premix 2 & $y=98.939 e^{-0.094 x}$ & 0.799 & 0.240 & 0.041 \\
\hline 19 & $\mathrm{VB}_{1}$ & VTM premix 3 & $y=99.533 e^{-0.081 x}$ & 0.876 & 0.157 & 0.019 \\
\hline 20 & $\mathrm{VB}_{1}$ & VTM premix 4 & $y=133.472 e^{-0.242 x}$ & 0.992 & 0.095 & $<0.001$ \\
\hline 21 & $\mathrm{VB}_{2}$ & VTM premix 1 & $y=97.178 e^{-0.01 x}$ & 0.810 & 0.026 & 0.037 \\
\hline 22 & $\mathrm{VB}_{2}$ & VTM premix 2 & $y=90.3 e^{-0.012 x}$ & 0.492 & 0.062 & 0.187 \\
\hline 23 & $\mathrm{VB}_{2}$ & VTM premix 3 & $y=97.393 e^{-0.003 x}$ & 0.477 & 0.018 & 0.217 \\
\hline 24 & $\mathrm{VB}_{2}$ & VTM premix 4 & $y=94.924 e^{-0.015 x}$ & 0.861 & 0.031 & 0.023 \\
\hline 25 & $\mathrm{VB}_{3}$ & VTM premix 1 & $y=98.349 e^{-0.004 x}$ & 0.838 & 0.009 & 0.029 \\
\hline 26 & $\mathrm{VB}_{3}$ & VTM premix 2 & $y=99.114 e^{-0.005 x}$ & 0.904 & 0.009 & 0.013 \\
\hline 27 & $\mathrm{VB}_{3}$ & VTM premix 3 & $y=99.292 e^{-0.006 x}$ & 0.774 & 0.016 & 0.049 \\
\hline 28 & $\mathrm{VB}_{3}$ & VTM premix 4 & $y=99.252 e^{-0.006 x}$ & 0.896 & 0.010 & 0.015 \\
\hline 29 & $\mathrm{VB}_{5}$ & VTM premix 1 & $y=100.996 e^{-0.006 x}$ & 0.884 & 0.012 & 0.017 \\
\hline 30 & $\mathrm{VB}_{5}$ & VTM premix 2 & $y=-0.672 x+101.276$ & 0.887 & 1.231 & 0.017 \\
\hline 31 & $\mathrm{VB}_{5}$ & VTM premix 3 & $y=-0.647 x+100.34$ & 0.907 & 0.908 & 0.008 \\
\hline 32 & $\mathrm{VB}_{5}$ & VTM premix 4 & $y=-0.62 x+101.288$ & 0.913 & 0.840 & 0.007 \\
\hline 33 & $\mathrm{VB}_{6}$ & VTM premix 1 & $y=-1.946 x+101.076$ & 0.998 & 0.437 & $<0.001$ \\
\hline 34 & $\mathrm{VB}_{6}$ & VTM premix 2 & $y=101.315 e^{-0.018 x}$ & 0.984 & 0.012 & 0.001 \\
\hline 35 & $\mathrm{VB}_{6}$ & VTM premix 3 & $y=101.667 e^{-0.027 x}$ & 0.810 & 0.067 & 0.037 \\
\hline 36 & $\mathrm{VB}_{6}$ & VTM premix 4 & $y=97.419 e^{-0.02 x}$ & 0.747 & 0.060 & 0.059 \\
\hline
\end{tabular}

VTM, vitamin-trace mineral; RMSEP, root mean square error of prediction; $V A$, vitamin $A ; V D_{3}$, vitamin $D_{3} ; V E$, vitamin $E_{;} V_{3}$, vitamin $K_{3} ; V_{1}$, vitamin $B_{1} ; V_{2}$, vitamin $\mathrm{B}_{2} ; \mathrm{VB}_{3}$; vitamin $\mathrm{B}_{3} ; \mathrm{VB}_{5}$, vitamin $\mathrm{B}_{5} ; \mathrm{VB}_{6}$, vitamin $\mathrm{B}_{6}$.

1) VTM premix 1 contained $500 \mathrm{mg} / \mathrm{kg}$ of $\mathrm{CuSO}_{4}$ and $8,000 \mathrm{mg} / \mathrm{kg}$ of $\mathrm{ZnO} ; \mathrm{VTM}$ premix 2 contained $40,000 \mathrm{mg} / \mathrm{kg}$ of choline chloride, $500 \mathrm{mg} / \mathrm{kg}$ of CuSO and $8,000 \mathrm{mg} / \mathrm{kg}$ of ZnO; VTM premix 3 contained 20,000 mg/kg of CuSO ${ }_{4}$ and 225,000 mg/kg of ZnO; VTM premix 4 contained $40,000 \mathrm{mg} / \mathrm{kg}$ of choline chloride, $20,000 \mathrm{mg} / \mathrm{kg}$ of $\mathrm{CuSO}_{4}$ and $225,000 \mathrm{mg} / \mathrm{kg}$ of $\mathrm{ZnO}$.

2) $y(\%)$ is retention of vitamin, $x$ (month) is storage time.

\section{DISCUSSION}

Extended storage time affected the stability of vitamins Determination of vitamin stability before and after storing is necessary to assess the final amount of actual vitamin that will reach the end-user and to calculate what amount should be added to any feed matrix. Storing vitamins for long periods has been considered to negatively affect vitamin activity in vitamin or VTM premixes. However, the results of our study indicate that long-term storage of vitamin premixes had little influence upon $\mathrm{VA}, \mathrm{VE}$, and $\mathrm{VB}_{3}$ concentrations. The results from our study agreed with previous studies on vitamin stability. Coelho [8] reported that the average loss per month of $\mathrm{VA}, \mathrm{VE}$, and $\mathrm{VB}_{3}$ after storage was $2.9 \%, 2.7 \%$, and $2.7 \%$, respectively. Because most manufactures of VA producers stabilize VA using the method of sealing within a physical matrix, generally arabic gum or gelatin $[2,18]$. In addition, in the production of commercially-available VA and VE, their hydroxy group is protected by the formation of an ester, as in $\alpha$-tocopherol acetate. The obtained $\alpha$-tocopherol acetate is resistant to oxygen, since it lacks double bonds $[3,9]$. In the present study, the retention of niacin was more than $90 \%$ after 1 year of storage, which is consistent with Zhuge and Klopfenstein [19], who reported that the reten- 
tion rate of $\mathrm{VB}_{3}$ during storage was $91 \%$ to $96 \%$ during 27 weeks storage. This was not surprising to us because $\mathrm{VB}_{3}$ has been reported to be the most stable among the $\mathrm{B}$ vitamins when added to feed or premixes [19] owing to its a stable molecular structure, which reduces its oxidation during storage. Coelho [8] reported that the loss of commercial fat-soluble vitamins after one month of storage was less than $10 \%$; after six months of storage, its loss rate was $10 \%$ to $60 \%$. Shurson et al [20] reported that vitamin activity in vitamin and VTM premixes decreased with prolonged storage time, but stability of $\mathrm{VE}, \mathrm{VB}_{2}, \mathrm{VB}_{3}, \mathrm{VB}_{5}$, and $\mathrm{VB}_{6}$ are higher than that of other vitamins, which is in line with our results.

\section{Addition of choline chloride affected vitamin stability}

Choline chloride has been reported to significantly affect vitamin activity [8-10]. Choline is considered a stress agent that affects vitamins that dissolve easily in water because it is hygroscopic, and can attract moisture to vitamin or VTM premixes [3]. The concentration of choline chloride in feed is usually higher than the micro-ingredient level, and problems related to both physical and chemical properties can be expected when choline is added to vitamin or VTM premixes [8-10]. After six months of storage, the loss of vitamin in a vitamin premix without choline chloride was $1 \%$ to $5 \%$ [8]; with choline chloride in the premix, the vitamin loss up to $32 \%$ after six months of storage [8]. In addition, the negative effects of choline chloride on vitamins in a VTM premix were more significant. After six months of storage, the loss of vitamin in a VTM premix without choline chloride was $12 \%$ to $30 \%$ [8]. However, in a VTM premix with choline chloride, the loss after six months was $23 \%$ to $52 \%$ [8]. Vitamin $\mathrm{K}$ is known for its contribution to the blood clotting or coagulation process. The $\mathrm{VK}_{3}$ was more stable in vitamin premix without choline than in the vitamin premix with choline during one-year storage, which was consistent with Tavčar-Kalcher and Vengušt [10]. Results from the present study suggest that loss of $\mathrm{VK}_{3}$ activity was approximately $60 \%$ in two vitamin premixes. Our results are similar to the average monthly losses reported by Coelho [8]. In the current study, choline chloride is a significant factor affecting the loss of $\mathrm{VK}_{3}$ activity. Menadione $\left(\mathrm{VK}_{3}\right)$ is the form of vitamin $\mathrm{K}$ that is used in animal nutrition. It is not utilized in pure form in premix plants but was formulated with sodium bisulfite and derivatives. The most common menadione compound used in the industry is the water-soluble salt, menadione sodium bisulfite. It was reported that $\mathrm{VK}_{3}$ was very sensitive to moisture and trace minerals, and choline chloride was particularly destructive to $\mathrm{VK}_{3}$ [10]. Furthermore, supplemented choline chloride in vitamin or VTM premixes increased leaching of $\mathrm{VK}_{3}$ and prolonged oxidation-reduction reactions $[9,10]$. The inclusion of choline chloride in a VTM premix contributes to $\mathrm{VA}, \mathrm{VK}_{3}, \mathrm{VB}_{1}$, and
$\mathrm{VB}_{2}$ instability during storage. Stability data published by BASF 1994, cited by Whitehead [21], showed VA, $\mathrm{VK}_{3}, \mathrm{VB}_{1}$, and $\mathrm{VB}_{2}$ loss of $15 \%, 36 \%, 30 \%$, and $5 \%$ after one month and $42 \%, 100 \%, 73 \%$, and $44 \%$ after six months of storage in VTM premixes containing choline chloride. Besides, we observed that loss of $\mathrm{VA}, \mathrm{VK}_{3}, \mathrm{VB}_{1}$, and $\mathrm{VB}_{2}$ was lower than that reported by Whitehead [21]. The reason may be that the vitamin manufacturing industry has developed products with improved stability. In the present study, we used thiamine mononitrate as $\mathrm{VB}_{1}$ source, it is used more often in feed because of its higher stability compared to thiamine hydrochloride $[3,8]$. In addition, the commercial form of $\mathrm{VA}$ and $\mathrm{VB}_{2}$ is spray-dried processing, which usually provides improved stability during storage and transportation.

\section{Excessive $\mathrm{Cu}$ and Zn elements in VTM premix affected vitamin stability}

The VTM premixes are the most common dietary supplements. In commercial conditions, feeding piglets with high concentrations of $\mathrm{Zn}$ and $\mathrm{Cu}$ stimulates their average daily gain, decreases the feed conversion ratio, improves the digestibility of dietary nutrients and growth performance, and decreases the incidence of diarrhea [6,7]. However, minerals in premixes are usually in an inorganic form: sulfates, chlorides, oxides, etc. Different metal compounds have different capability of catalytic oxidation reaction [8]. In the present study, high levels of $\mathrm{CuSO}_{4}$ (more than $20,000 \mathrm{mg} / \mathrm{kg}$ of $\mathrm{Cu}$ in premix to promote growth) and $\mathrm{ZnO}$ (more than 225,000 $\mathrm{mg} / \mathrm{kg}$ of $\mathrm{Zn}$ in premix to decrease the incidence of diarrhea) in VTM premixes resulted in the degradation of vitamins. Vitamin stability is reduced in the presence of certain trace minerals $[8,9,20]$. In our study, blending vitamins with trace minerals to form VTM premixes increased the loss of vitamin activity during prolonged storage periods. These trace minerals in premix can catalyze the generation of free radicals, thereby oxidizing antioxidants during storage. Certain metal-catalyzed destruction of vitamins in the feed matrix has been reviewed previously to a limited extent [22]. Trace minerals vary in their redox potential: $\mathrm{Cu}, \mathrm{Fe}$, and $\mathrm{Zn}$ are the most reactive, and $\mathrm{Se}, \mathrm{I}$, and $\mathrm{Mg}$ are less reactive minerals $[8,22]$. Reactive trace minerals reduce vitamin activity by oxidizing the vitamins. First, the metallic-like nature of trace minerals reduces the crystals of vitamins to smaller particles by eroding their protective coating. The smaller particles provide increased surface areas of vitamins for reactions between vitamin particles and trace mineral particles.

Dove and Ewan [23] reported that a high concentration of $\mathrm{Cu}(250 \mathrm{mg} / \mathrm{kg}$ feed) or $\mathrm{Zn}(1,000 \mathrm{mg} / \mathrm{kg}$ feed) increased vitamin loss. Redox-active transition metals, such as $\mathrm{Cu}$, can serve as catalysts for the oxidation of organic compounds. $\mathrm{Lu}$ et al [24] reported that a high concentration of $\mathrm{Cu}$ sulfate promoted the undesirable oxidation of VE in feeds. Intrigu- 
ingly, we did not find significant effects on VE content in the four VTM premixes during long-term storage. There are two significant factors that might contribute to achieve this positive characteristic. First, supplementation of VE are generally given in the form of all-rac- $\alpha$-tocopheryl acetate in which the reactive hydroxyl group of $\alpha$-tocopherol is esterified; rendering the molecule more stable than the free phenol form, and second, production of VE provides a physical barrier to reduce surface contact with pro-oxidant agents such as $\mathrm{Zn}$ or $\mathrm{Cu}$. On the other hand, we observed long-term storage of VTM premix with high concentrations of $\mathrm{Cu}$ and $\mathrm{Zn}$ had no effect on $\mathrm{VB}_{3}$ and $\mathrm{VB}_{5}$ concentrations. The results from our study confirm previous studies on the stability of these vitamins. Shurson et al [20] reported recovery of $\mathrm{VB}_{3}$ after 120 days of storage in a vitamin stock was $96.68 \%, 86.04 \%$ in vitamin premix, and $87.04 \%$ in VTM premix. Zhuge and Klopfenstein [19] also reported that $\mathrm{VB}_{3}$ was considerably more stable than other vitamins; at the end of 27 weeks storage, $\mathrm{VB}_{3}$ in premixes with or without mineral retained $91 \%$ and $96 \%$, respectively. The $\mathrm{VB}_{3}$ is probably the most stable of the water-soluble vitamins when added to feed or premixes, being little affected by heat, oxygen, moisture, or light $[3,11]$. However, there are no reports on the mechanism of resistance to degradation or subsequent degradation products. The $\mathrm{VB}_{5}$, pantothenic acid, is a constituent of coenzyme A, which both act as carriers of acyl groups and activators of carbonyl groups in many metabolic processes $[2,3]$. Pure $\mathrm{VB}_{5}$ is a viscous, hygroscopic, and chemically-unstable oil. In premixes, this vitamin is commonly added as calcium pantothenate, a soluble and stable solid. The calcium salt is preferred to the sodium salt, as solid forms of the sodium salt are much more hygroscopic. Similar to niacin, there were no significant influences of choline and high concentrations of $\mathrm{Cu}$ and $\mathrm{Zn}$ on pantothenic acid retention in VTM premixes. But storage time was a significant factor affecting the loss of $\mathrm{VB}_{5}$ under ambient temperature and relative humidity [3]. According to the previous results [20], there was no significant difference in the stability of $\mathrm{VB}_{5}$ after 120 days of storage at vitamin stock, vitamin premix and vitamininorganic trace minerals premix. A similar result was reported by Coelho [8]. Furthermore, it was reported that pantothenic acid was relatively stable to heat, oxygen, and light [8]. The stability of pantothenic acid is due to the presence of the carboxylic acid group to form two hydrogen bonds between a pair of molecules [25]. Furthermore, the amide group and two methyl groups in the aliphatic chain of pantothenic acid contribute to its stability.

In the current study, the supplementation of high concentrations of $\mathrm{Cu}$ and $\mathrm{Zn}$ significantly reduced the concentrations of $\mathrm{VA}, \mathrm{VD}_{3}, \mathrm{VK}_{3}, \mathrm{VB}_{1}, \mathrm{VB}_{2}$, and $\mathrm{VB}_{6}$ in VTM premixes during storage. The reason can be explained that the presence of $\mathrm{Zn}$ and $\mathrm{Cu}$ in premix can speed up vitamin degradation $[3,8$,
9], these minerals can catalyze the generation of free radicals which can oxidize vitamins in VTM premixes. Also, the results from our study confirm previous studies on vitamin stability in VTM premix. Shurson et al [20] reported that the stability of $\mathrm{VA}, \mathrm{VK}_{3}, \mathrm{VB}_{1}$, and $\mathrm{VB}_{6}$ in premixes was influenced by the presence of trace minerals. These results were in line with previous study. Yang et al [9] reported that stability of $\mathrm{VA}, \mathrm{VB}_{1}$, and $\mathrm{VB}_{6}$ was affected by trace minerals, and the premixes containing high levels of $\mathrm{Cu}$ and $\mathrm{Zn}$ was more susceptible to oxidative reaction of vitamins. Factors that reduce VA activity are atmospheric oxygen, light, heat and other oxidizing agents [3]. Manan et al [26] looked at the stability of VA in the presence of $\mathrm{Cu}$ and $\mathrm{Zn}$; the results showed that mineral fortification reduced VA stability by $36 \%$. Pinkaew et al [27] reported the stability of VA in the presence of $\mathrm{ZnO}$; the results showed that mineral fortification reduced the VA stability by $13.4 \%$. The chemical structure of VA is an unsaturated monohydric alcohol with 20 carbon atoms, consisting of a cyclohexane ring linked to a polyunsaturated chain that terminates in an alcohol group. The five conjugated double bonds in the configuration of VA are easy points of attack for oxygen. The oxidation of the alcohol end group of VA results in the formation of retinal or all-trans retinaldehyde, which can be further oxidized to all-trans retinoic acid. Besides, the structure of $\mathrm{VB}_{1}$ can help to understand its instability during storage. The methylene bridge connecting the pyrimidine and thiazole moiety can easily be broken down by oxidizing ingredients [25]. In addition, the $\mathrm{VB}_{6}$ comprises a group of three related compounds: pyridoxine, pyridoxal, and pyridoxamine. Pyridoxine is commonly used for feed because pyridoxine is more stable than either pyridoxal or pyridoxamine [3,8], but pyridoxine was sensitive to light, particularly in neutral and alkaline solutions. The $\mathrm{VB}_{6}$ can lose bioactivity, particularly when minerals in the form of carbonates or oxides are present $[8,11]$. In the current study, the supplementation of high concentrations of $\mathrm{Cu}$ and $\mathrm{Zn}$ significantly reduced the concentrations of $\mathrm{VB}_{6}$ in VTM premixes during storage. The loss of $\mathrm{VB}_{6}$ activity after three months of storage at room temperature was $24 \%$ [11], which was slightly higher than $\mathrm{VB}_{6}$ loss in the present study. It may be that the degradation reaction of $\mathrm{VB}_{6}$ was enhanced by metal ions in the previous study. Loss of $\mathrm{VB}_{6}$ was lower when stored as vitamin premixes compared to VTM premixes, maybe the reason was that VTM premix contained more trace mineral. In VTM premixes, $\mathrm{VB}_{6}$ can lose bioactivity, particularly when minerals in the form of carbonates or oxides are present $[8,11]$. We used pyridoxine hydrochloride in the present trial, which is a commercially available form. And pyridoxine hydrochloride is the main supplement used in feed, because it has good handling properties and stability. In addition, Coelho [8] reported the loss of $\mathrm{VB}_{6}$ after six months of storage in a 
vitamin premix was $17 \%$, and $32 \%$ in a VTM premix. Although the retention rate of $\mathrm{VB}_{6}$ in Coelho's study [8] was completely inconsistent with our results, our data also show that the stability of $\mathrm{VB}_{6}$ is reduced in the premix containing inorganic trace minerals.

There are very limited stability data available for $\mathrm{VD}_{3}$ and $\mathrm{VB}_{2}$ in VTM premixes. The supplementation of high concentrations of $\mathrm{Cu}$ and $\mathrm{Zn}$ decreased the stability of $\mathrm{VD}_{3}$ and $\mathrm{VB}_{2}$ in VTM premixes in the present study. The $\mathrm{VD}_{3}$ is a fundamentally unstable compound containing double bounds that can be altered by different stresses and prone to degradation due to oxidation $[3,28]$. The stability of VD to oxidation and its instability to trace minerals were also reported by previous studies; Mahmoodani et al [28] demonstrated catalyzed isomerization of $\mathrm{VD}_{3}$ is liable via autoxidation to form a variety of oxidation products. Further, Zhuge and Klopfenstein [19] reported that $\mathrm{VB}_{2}$ was destroyed faster in the premix containing minerals and $54 \%$ of $\mathrm{VB}_{2}$ had been destroyed after 27 weeks of storage. In the last case, the loss of $\mathrm{VB}_{2}$ after six months of storage was $44 \%$ cited by Whitehead [21]. The most well-characterized aspect of riboflavin reactivity is its sensitivity to light in an aerobic environment which may be one of the reasons for low $\mathrm{VB}_{2}$ retention of previous studies. The rate of degradation can be promoted by complexation with some metal cations (e.g., $\mathrm{Cu}^{2+}$ and $\mathrm{Zn}^{2+}$ ) at the isoalloxazine moiety [29]. Vitamin $\mathrm{A}, \mathrm{VD}_{3}, \mathrm{VK}_{3}, \mathrm{VB}_{1}, \mathrm{VB}_{2}$, and $\mathrm{VB}_{6}$ are relatively stable in vitamin premix, but degradation of vitamin was potentiated by the chemical reaction caused by the presence of $\mathrm{Cu}$ and $\mathrm{Zn}$ elements.

\section{Prediction equations for vitamin retention in premixes during storage}

Prediction equations have been widely used to estimate values through regression analysis and can be a suitable proxy for conducting relevant experiments (i.e. loss in vitamin stability with time) and thus save time, reduce cost, and improve precision in diet formulation. To establish prediction equations of vitamin content in premix from storage time, regression analysis programming was used. The degradation of most of the vitamins followed first-order kinetics that can be developed $[9,30]$. The degradation rate accelerated progressively with storage time in vitamin and VTM premixes. What is more, $\mathrm{VA}, \mathrm{VK}_{3}, \mathrm{VB}_{1}, \mathrm{VB}_{2}$, and $\mathrm{VB}_{6}$ degraded rapidly in $\mathrm{VTM}$ premix containing choline and high concentrations of $\mathrm{Cu}$ and $\mathrm{Zn}$. When comparing the relative retention of vitamins, the data showed a significant deviation in different VTM premix. The VTM premix 4 has the most prominent sensitivity, followed by VTM premix 3 and 2. These observations are in line with previous report [9], showing poor vitamin retention in VTM premix containing choline and trace minerals. This differing behavior regarding vitamin degradation can be attributed to difference premix formulation and the presence of more metal ions, such as $\mathrm{Cu}^{2+}$ and $\mathrm{Zn}^{2+}$ that act as catalysts. The degradation of vitamins does not always increase linearly during storage, and the majority of predicted equations had good fit with the experimental data. This study is consistent with Giannakourou et al [30] who also found vitamin loss due to storage time was well predicted by exponential models. For prediction of vitamin loss during storage with non-linear kinetic models, this method has been proved effective to extract the kinetics parameters for vitamin degradation [31]. To the best of our knowledge, the degradation kinetics of vitamin in VTM premixes had not been studied before. The purpose of present study was to establish kinetic equations for vitamin retention in different premixes during storage. Validated kinetic models of vitamin for VTM premix, can be used for evaluation, control and proper management of the premix, with the application of suitable time indicators. Further, these results can serve for vitamin and VTM premixes production in order to improve the knowledge of vitamin its stability.

\section{CONCLUSION}

The present study has provided information on the kinetics of vitamin degradation in different premixes during storage. The degradation of vitamins in all the samples under all storage conditions followed the first-order kinetics. Stability of VA, $\mathrm{VK}_{3}, \mathrm{VB}_{1}, \mathrm{VB}_{2}$, and $\mathrm{VB}_{6}$ was higher in VTM premixes containing no choline or high concentrations of $\mathrm{Cu}$ and $\mathrm{Zn}$. The high concentration of trace minerals in the VTM premix can negatively affect $\mathrm{VD}_{3}$ stability. Our study also suggested that considering the potential losses of vitamins in formulation, the time between the manufacturing and use of the vitamin premixes should be minimized, and vitamins and trace mineral premixes should be stored separately. This work could be used as a guideline for the fortification of vitamin and VTM premixes.

\section{CONFLICT OF INTEREST}

We certify that there is no conflict of interest with any financial organization regarding the material discussed in the manuscript. Zhu M is an employee of Liyuan Group.

\section{ACKNOWLEDGMENTS}

This study was financially supported by the China Agricultural University Research Funding (201705510410056) and Ministry of Agriculture and Rural Affairs Funding (21178259). The authors express their appreciation to the staff of Ministry of Agriculture and Rural Affairs Feed Efficacy and Safety Evaluation Center (Beijing, China) for sample analyses. We want to thank Prof. Crystal Levesque in South Dakota State 
University for revising the manuscript. Also, I want to show my appreciation for Eason Chan; when a grey person walking a grey wall in a grey campus, the melody 'Ren Lai Ren Wang, Tao Tai, and Bitter Gourd' grew and passed my soul; Thanks to rekindle my heart in the dark.

\section{REFERENCES}

1. Jang YD, $\mathrm{Ma}$ J, $\mathrm{Lu} \mathrm{N}$, et al. Administration of vitamin $\mathrm{D}_{3}$ by injection or drinking water alters serum 25-hydroxycholecalciferol concentrations of nursery pigs. Asian-Australas J Anim Sci 2018;31:278-86. https://doi.org/10.5713/ajas.17. 0397

2. Teleki A, Hitzfeld A, Eggersdorfer M. 100 years of vitamins: the science of formulation is the key to functionality. Kona Powder Part J 2013;30:144-63. https://doi.org/10.14356/kona. 2013015

3. Combs GF, McClung JP. The vitamins: fundamental aspects in nutrition and health. 5th ed. Cambridge, MA, USA: Academic Press; 2016.

4. Li W, Li B, Lv J, Dong L, Zhang L, Wang T. Choline supplementation improves the lipid metabolism of intrauterinegrowth-restricted pigs. Asian-Australas J Anim Sci 2018;31: 686-95. https://doi.org/10.5713/ajas.15.0810

5. Hill GM, Mahan DC, Carter SD, et al. Effect of pharmacological concentrations of zinc oxide with or without the inclusion of an antibacterial agent on nursery pig performance. J Anim Sci 2001;79:934-41. https://doi.org/10.2527/2001.794934x

6. Shelton NW, Tokach MD, Nelssen JL, et al. Effects of copper sulfate, tri-basic copper chloride, and zinc oxide on weanling pig performance. J Anim Sci 2011;89:2440-51. https://doi. org/10.2527/jas.2010-3432

7. Zhang G, Xia T, Zhao J, et al. Moderate tetrabasic zinc chloride supplementation improves growth performance and reduces diarrhea incidence in weaned pigs. Asian-Australas J Anim Sci 2020;33:264-76. https://doi.org/10.5713/ajas.18.0914

8. Coelho M. Vitamin stability in premixes and feeds: a practical approach in ruminant diets. In: Proceedings of the 13th Annual Florida Ruminant Nutrition Symposium; 2002: FL, USA. pp. 127-45.

9. Yang P, Wang H, Zhu M, Ma Y. Effects of choline chloride, copper sulfate and zinc oxide on long-term stabilization of microencapsulated vitamins in premixes for weanling piglets. Animals 2019;9:1154. https://doi.org/10.3390/ani9121154

10. Tavčar-Kalcher G, Vengušt A. Stability of vitamins in premixes. Anim Feed Sci Technol 2007;132:148-54. https://doi.org/10. 1016/j.anifeedsci.2006.03.001

11. Baker DH. Bioavailability of minerals and vitamins. In: Lewis AJ, Southern LL, editors. Swine nutrition. 2nd ed. Boca Raton, FL, USA: CRC Press; 2001. pp. 357-80.

12.Standardization Administration of China. Determination of choline chloride in premix. GB/T 17481-2008. Beijing,
China: Administration of Quality Supervision, Inspection and Quarantine of People's Republic of China; 2008.

13.Committee on Nutrient Requirements of Swine, National Research Council. Nutrient requirements of swine. 11th ed. Washington, DC, USA: National Academies Press; 2012.

14.Latimer GW. Official methods of analysis of AOAC International. 19th ed. Gaithersburg, MD, USA: AOAC International; 2012.

15. China National Standardization Administration. Feed additive - menadione sodium bisulfite (vitamin K3). GB 7294-2017. Beijing, China: General Administration of Quality Supervision, Inspection and Quarantine of People's Republic of China; 2017.

16. Chen P, Atkinson R, Wolf WR. Single-laboratory validation of a high-performance liquid chromatographic-diode array detector-fluorescence detector/mass spectrometric method for simultaneous determination of water-soluble vitamins in multivitamin dietary tablets. J AOAC Int 2009;92:680-7.

17. Tiwari BK, O’Donnell CP, Muthukumarappan K, Cullen PJ. Ascorbic acid degradation kinetics of sonicated orange juice during storage and comparison with thermally pasteurised juice. LWT Food Sci Technol 2009;42:700-4. https://doi.org/ 10.1016/j.lwt.2008.10.009

18. Gonçalves A, Estevinho BN, Rocha F. Microencapsulation of vitamin A: a review. Trends Food Sci Technol 2016;51:7687. https://doi.org/10.1016/j.tifs.2016.03.001

19.Zhuge Q, Klopfenstein CF. Factors affecting storage stability of vitamin a, riboflavin, and niacin in a broiler diet premix. Poult Sci 1986;65:987-94. https://doi.org/10.3382/ps.0650987

20.Shurson GC, Salzer TM, Koehler DD, Whitney MH. Effect of metal specific amino acid complexes and inorganic trace minerals on vitamin stability in premixes. Anim Feed Sci Technol 2011;163:200-6. https://doi.org/10.1016/j.anifeedsci. 2010.11.001

21. Whitehead CC. Vitamins in feedstuffs. In: McNab JM, Boorman KN, editors. Poultry feedstuffs: supply, composition and nutritive value. Wallingford, UK: CABI Publishing; 2002. pp. 181-90.

22. Rabovsky AB, Komarov AM, Ivie JS, Buettner GR. Minimization of free radical damage by metal catalysis of multivitamin/ multimineral supplements. Nutr J 2010;9:61. https://doi.org/ 10.1186/1475-2891-9-61

23. Dove CR, Ewan RC. Effect of trace minerals on the stability of vitamin E in swine grower diets. J Anim Sci 1991;69:19942000. https://doi.org/10.2527/1991.6951994x

24.Lu L, Wang RL, Zhang ZJ, Steward FA, Luo X, Liu B. Effect of dietary supplementation with copper sulfate or tribasic copper chloride on the growth performance, liver copper concentrations of broilers fed in floor pens, and stabilities of vitamin E and phytase in feeds. Biol Trace Elem Res 2010; 138:181-9. https://doi.org/10.1007/s12011-010-8623-3

25. Muhamad N, Yusoff MM, Gimbun J. Thermal degradation kinetics of nicotinic acid, pantothenic acid and catechin 
derived from Averrhoa bilimbi fruits. RSC Adv 2015;5:741327. https://doi.org/10.1039/C5RA11950B

26. Manan F, Guevara LV, Ryley J. The stability of all-trans retinol and reactivity towards transition metals. Food Chem 1991; 40:43-54. https://doi.org/10.1016/0308-8146(91)90018-J

27.Pinkaew S, Wegmuller R, Hurrell R. Vitamin A stability in triple fortified extruded, artificial rice grains containing iron, zinc and vitamin A. Int J Food Sci Technol 2012;47:221220. https://doi.org/10.1111/j.1365-2621.2012.03091.x

28. Mahmoodani F, Perera CO, Fedrizzi B, Abernethy G, Chen $\mathrm{H}$. Degradation studies of cholecalciferol (vitamin $\mathrm{D}_{3}$ ) using HPLC-DAD, UHPLC-MS/MS and chemical derivatization. Food Chem 2017;219:373-81. https://doi.org/10.1016/j.food chem.2016.09.146

29. Ahmad I, Anwar Z, Ahmed S, Sheraz MA, Khattak SR. Metal ion mediated photolysis reactions of riboflavin: a kinetic study. J Photochem Photobiol B Biol 2017;173:231-9. https://doi. org/10.1016/j.jphotobiol.2017.05.033

30. Giannakourou MC, Taoukis PS. Kinetic modelling of vitamin $\mathrm{C}$ loss in frozen green vegetables under variable storage conditions. Food Chem 2003;83:33-41. https://doi.org/10.1016/ S0308-8146(03)00033-5

31.Corradini MG, Peleg M. Prediction of vitamins loss during non-isothermal heat processes and storage with non-linear kinetic models. Trends Food Sci Technol 2006;17:24-34. https://doi.org/10.1016/j.tifs.2005.09.004 